\title{
POLÍTICA LINGUÍSTICA OFICIAL PARA A EDUCAÇÃO EM LIBRAS NO ESTADO DE PERNAMBUCO: UM PANORAMA DE DUAS DÉCADAS (1999-2019)
}

\author{
Official language policy for Brazilian Sign Language education in the state \\ of Pernambuco: a two-decade overview (1999-2019)
}

\author{
Rafaela Cristina Oliveira de ANDRADE \\ Universidade Federal da Paraíba \\ rafaela.oliveirandrade@hotmail.com \\ https://orcid.org/0000-0002-0194-0980
}
Cynthia Israelly Barbalho DIONÍSIO
Universidade Federal da Paraíba cynthiadionisio@live.com
https://orcid.org/0000-0001-8666-1122

RESUMO: Neste artigo, discutimos as políticas linguísticas educacionais oficiais de Pernambuco voltadas para a Libras, no período de 1999 a 2019, com base em uma amostra de documentos oficiais. Nossa base teórica são as noções de política linguística e domínio escolar (SPOLSKY, 2004, 2009), de mecanismos (SHOHAMY, 2006) e de política linguística como processo (JOHNSON, 2013). O estudo, de natureza documental, segue a metodologia qualitativo-interpretativista. A análise textual se baseia em Koch (2000, 2011). Evidenciamos como os documentos oficiais analisados representam o gerenciamento linguístico exercido por Pernambuco, que aciona diversos mecanismos para fortalecer a Libras no sistema educacional do estado. Tais documentos são formulados em um processo dinâmico e interativo que resulta em textos que refletem diversas vozes sociais. Contudo, a prática ainda está aquém da legislação, cabendo um esforço dos agentes envolvidos com o contexto surdo para que esse amplo acervo documental possa se traduzir na prática.

PALAVRAS-CHAVE: Política linguística; Libras; Educação de surdos; Pernambuco.

ABSTRACT: In this article, we discuss Pernambuco's official educational language policies aimed at Brazilian Sign Language (Libras), from 1999 to 2019, based on a sample of official documents. Our theoretical view is based on the notions of language policy and school domain (SPOLSKY, 2004, 2009), mechanisms (SHOHAMY, 2006) and language policy as a process (JOHNSON, 2013). The study is a documental analysis and it follows a qualitative-interpretative 
methodology. Text analysis is based on Koch $(2000,2011)$.We highlight how the official documents analyzed represent the language management exercised by Pernambuco, which triggers several mechanisms to strengthen Libras in the state's educational system.Such documents are formulated in a dynamic and interactive process that results in texts that reflect different social voices. However, the practice still falls short of the legislation, and the agents involved with the deaf context should make an effort so that this broad document collection can be translated into practice.

KEYWORDS: Language policy; Brazilian Sign Language; Deaf education; Pernambuco.

\section{INTRODUÇÃO}

A trajetória das políticas públicas para surdos no Brasil é resultado de lutas de uma comunidade empenhada em fortalecer a sua identidade, a partir do reconhecimento de sua língua. Esse reconhecimento foi responsável por converter um caminho de desventuras (SACKS, 2010) em oportunidades, dando ao surdo o direito de ser surdo e de ser reconhecido socialmente por uma língua que o representa: a Língua Brasileira de Sinais (Libras).

No Brasil, os esforços para o fortalecimento da Libras resultaram na Lei Federal $\mathrm{n}^{\circ}$ 10.436/2002, que reconhece a língua e determina o seu ensino (BRASIL, 2002) e no Decreto $^{\circ}$ 5.626/2005, que regulamenta a lei federal (BRASIL, 2005). Essas leis nacionais subsidiaram novas discussões e avanços para a comunidade surda, a exemplo da Lei $\mathrm{n}^{\circ} 12.319 / 2010$, que regulamenta o exercício da profissão do tradutor e intérprete de Libras (BRASIL, 2010); e do Decreto n 9.465/2019, que cria a Diretoria de Políticas de Educação Bilíngue de Surdos, vinculada ao Ministério da Educação (BRASIL, 2019a).

Contudo, o movimento nacional de reconhecimento da Libras foi precedido por outras iniciativas de âmbito estadual. Neste estudo, de natureza documental (GIL, 2019), nosso objetivo é discutir as políticas linguísticas educacionais oficiais do estado de Pernambuco voltadas para a Libras, no período de 1999 a 2019, com base em documentos oficiais.Na discussão, exploramos o contexto de produção desses textos e realizamos uma análise linguística segundo Koch $(2000,2011)$, tendo como base as noções teóricas de política linguística e de domínio escolar de Spolsky (2004, 2009), de mecanismos de Shohamy (2006) e de política linguística como processo de Johnson (2013). Com isso, 
construímos um breve panorama normativo estadual e fornecemos subsídios para uma reflexão sobre o que foi feito dentro desse período histórico na legislação e na prática. A leitura do artigo pode ser de interesse para profissionais envolvidos com o contexto surdo em Pernambuco e para pesquisadores interessados nas políticas linguísticas oficiais direcionadas ao surdo no Brasil.

Organizamos este artigo em uma primeira seção introdutória, seguida de uma segunda seção que apresenta as noções teóricas adotadas, e uma terceira de discussão dos documentos. Na quarta e última seção, tecemos algumas considerações finais.

\section{POLÍTICA LINGUÍSTICA OFICIAL: GERENCIAMENTO MECANISMOS E PROCESSO DE FORMULAÇÃO LEGISLATIVA}

ESTATAL,

Para discutir as políticas linguísticas educacionais do estado de Pernambuco materializadas em documentos oficiais, primeiramente esclarecemos o que entendemos por “política linguística”, "mecanismos" e "processo político-linguístico".

Spolsky $(2004,2009)$ conceitua política linguística como um fenômeno que se manifestanas práticas de linguagem, nas crenças e ideologias, e no gerenciamento linguístico. De modo geral, as práticas de linguagem compreendem as escolhas linguísticas (conscientes ou não) que demarcam uma determinada variedade. Já as crenças e ideologias dizem respeito aos julgamentos sobre a propriedade de determinados usos linguísticos, bem como às valorações destinadas a eles. Por sua vez, o gerenciamento linguístico se refere à intervenção consciente e deliberada de uma pessoa ou grupo nos usos e nas crenças linguísticas, e geralmente é feito através da formulação de um plano explícito materializado em algum documento formal. Para o autor, todas essas dimensões constituiriam políticas linguísticas em si mesmas e interagiriam de maneira dinâmica entre elas e também com outros fatores não linguísticos (SPOLSKY, 2004, 2009).

Outra característica da política linguística, para Spolsky $(2004,2009)$, é que ela é uma prática social que se realiza em diversos domínios, caracterizados pela integração entre: i) participantes que desempenham papéis e relações sociais; ii) lugar como espaço de desempenho dessas relações sociais; e iii) tópico como tema ou objetivo central. A aplicação do conceito de domínio às investigações em política linguística favorece uma compreensão situada do fenômeno, uma vez que ajuda a estabelecer limites e 
possibilidades de atuação da política linguística nas famílias, hospitais, igrejas, Estados, organismos supranacionais etc.

No panorama spolskyano, a escola é classificada como um domínio específico. Os participantes (alunos, professores, diretores etc.) se reúnem em estabelecimentos educacionais cuja função precípua é desenvolver atividades relacionadas ao ensinoaprendizagem de diversos conteúdos disciplinares. Um aspecto importante da política linguística educacional é a decisão sobre a língua em que os conhecimentos escolares serão veiculados, bem como a língua sobre a qual se aprenderá, ou seja, que constituirá ela própria um conteúdo disciplinar (língua estrangeira, adicional etc.). A ideia de domínio é heurística, uma vez que os domínios se comunicam e se influenciam, ao mesmo tempo em que um domínio pode exercer regulação sobre outro. O domínio escolar, por exemplo, é profundamente influenciado pelas políticas linguísticas educacionais do domínio estatal, que procuram normatizá-lo, dentre outras.

No lastro da concepção de Spolsky (2004, 2009), Shohamy (2006) introduz o conceito de "mecanismos", que seriam dispositivos explícitos e implícitos que permitiriam a criação, a reprodução e a modificação da política linguística. Tais mecanismos funcionariam como "ferramentas" de intermediação e transmissão de ideologias para as práticas de linguagem e estariam dispersos em diversos domínios do cotidiano. Shohamy (2006) os elenca em categorias amplas: regras e normas, educação linguística, testes linguísticos, linguagem no espaço público, e ideologia, mitos, propaganda e coerção (Figura 1). 
Figura 1 - Mecanismos de Política Linguística

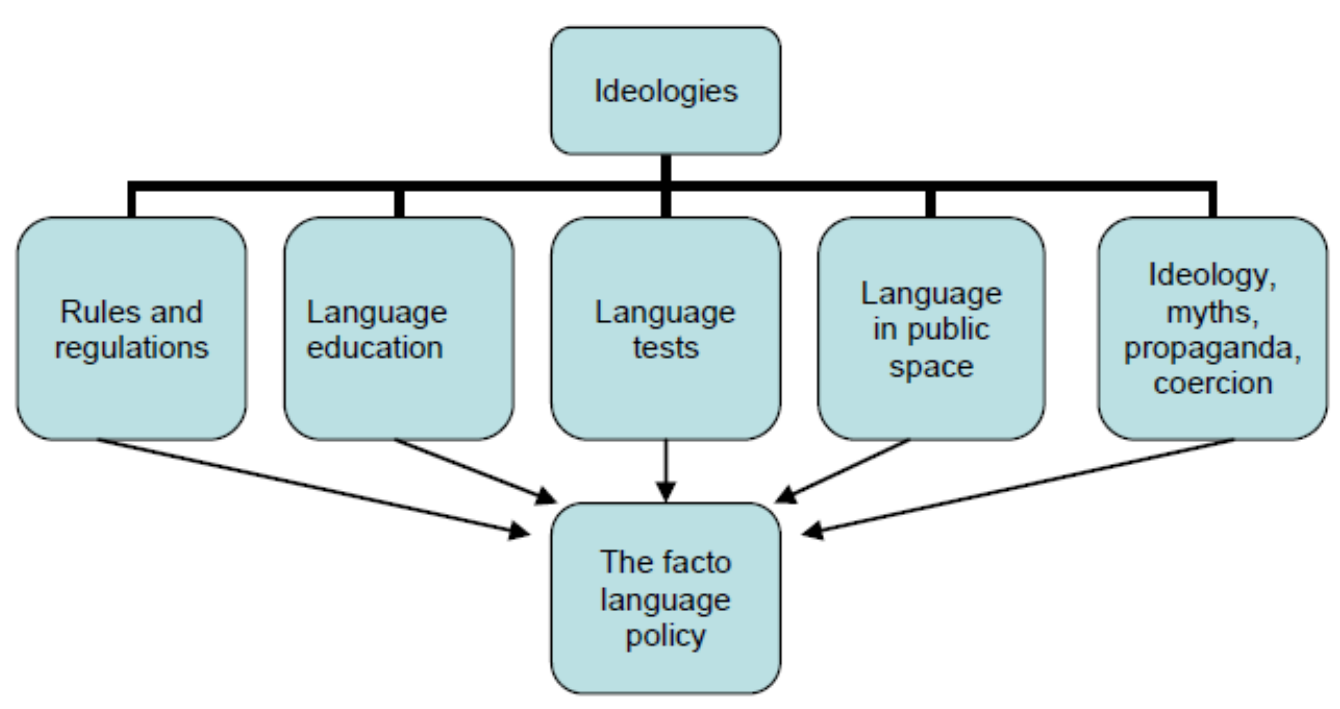

Fonte: Shohamy (2006, p. 58).

Não pretendendo uma discussão exaustiva sobre os mecanismos, sublinhamos que o domínio escolar está repleto deles. Por exemplo, as regras e normas permeiam todo o contexto escolar, através de documentos oficiais governamentais, institucionais e até mesmo produzidos por docentes. Os mecanismos da educação linguística (currículo, material didático, metodologias, formação de professores etc.) também têm na escola a sua razão de ser, bem como os testes linguísticos, que encontram nesse domínio pessoas ávidas a se preparar para eles em busca de sucesso acadêmico e profissional. Ainda, as escolas são permeadas por manifestações de linguagem no interior do seu espaço, bem como se pautam por determinadas ideologias e mitos, veiculam propagandas ideológicas e detêm instrumentos de coerção linguística. Por tudo isso, consideramos que o domínio escolar é um "pivô" de mecanismos de política linguística.

Johnson (2013) defende que a política linguística é um processo movido "por uma diversidade de agentes de políticas linguísticas, através das múltiplas camadas de criação, interpretação, apropriação, e instanciação" (JOHNSON, 2013, p. 09, grifos nossos ${ }^{1}$ ). Ao refletir sobre a fase da criação, o autor discute a complexidade de se debruçar sobre as intenções de textos legislativos, dado que são compostos por um emaranhado de vozes, que os fazem ideologicamente cacofônicos e heterogêneos. As políticas linguísticas

\footnotetext{
${ }^{1}$ Doravante todos os grifos em citações são nossos, a não ser quando houver indicação contrária.
} 
oficiais são criadas a partir do consenso entre vários atores sociais, obtido por meio de concessões,as quais satisfazem a todos parcialmente e a ninguém completamente (JOHNSON, 2013).

Fundamentadas nessas três contribuições teóricas: a de gerenciamento linguístico como dimensão da política linguística, de mecanismos de política linguística e de política linguística como processo composto por vários atores e etapas, que passamos à discussão das políticas linguísticas educacionais oficiais de Pernambuco voltadas para a Libras, no período de 1999 a 2019, com base em uma amostra de documentos oficiais.

\section{POLÍtica Linguística EDUCACIONAL DE PERNAMBUCO PARA A LIBRAS}

Nesta seção, discutimos documentos representativos da política linguística educacional de Pernambuco para a Libras, prestando atenção à sua construção textualdiscursiva $(\mathrm{KOCH}, 2000,2011)$ e às noções teóricas mobilizadas na fundamentação (SPOLSKY, 2004, 2009; SHOHAMY, 2006; JOHNSON, 2013).

Os seguintes documentos compõem o nosso corpus, a saber: Lei ${ }^{\circ} 11.686$ de 18 de outubro de 1999 - "Lei de Libras de Pernambuco"; Lei no 12.252, de 08 de julho de 2002 - Plano Estadual de Educação de 2002; Lei n ${ }^{\circ}$ 12.757, de 24 de janeiro de 2005; Lei $n^{\circ} 15.533$, de 23 de junho de 2015 - Plano Estadual de Educação de 2015; Edital nº 02, de 11 de dezembro de 2015 - Portaria conjunta SAD/SEE no 111 de 11 de dezembro de 2015; Instrução normativa SEE nº 007/2017; Decreto n 48.477, de 26 de dezembro de 2019 Regimento Interno Unificado; e os Currículos de Pernambuco para o Educação Infantil e para o Ensino Fundamental (PERNAMBUCO, 1999, 2002, 2005, 2015a, 2015b, 2017, 2019a, 2019b).

\section{Lei $\mathbf{n}^{\circ}$ 11.686, de 18 de outubro de 1999}

A ementa do texto legislativo estadual, que chamaremos aqui de "Lei de Libras de Pernambuco", estabelece seu objetivo precípuo: "Reconhece oficialmente no Estado de Pernambuco, como meio de comunicação objetiva e de uso corrente, a Língua Brasileira 
de Sinais (LIBRAS) ${ }^{2}$, e dispõe sobre a implantação desta como língua oficial na Rede Pública de ensino para surdos" (PERNAMBUCO, 1999).

No primeiro artigo da lei, incluindo o seu parágrafo único, há a tentativa de definir o objeto da matéria legislada. Nesse excerto, aparecem duas vozes textuais polifônicas que se alternam na definição da Libras: a do Estado e a do surdo.Para o Estado, a Libras seria uma "linguagem gestual codificada", um "meio de comunicação objetiva e de uso corrente, "um meio de comunicação de natureza visual-motora, com estrutura gramatical própria, oriunda de comunidades de pessoas surdas". Para o surdo, porém, a Libras seria uma "forma de expressão", mas também a sua "língua natural".

Segundo Johnson (2013), por ser fruto de consenso entre legisladores e outros setores sociais participativos, o texto legislativo é permeado por vozes diversas que se refletem em diversas orientações textual-discursivas presentes na versão final de uma lei. A polifonia textual na definição indica o momento histórico materializado no texto legal, uma vez que ainda não se tinha um consenso sobre o estatuto da Libras. Isso porque os primeiros esforços feitos pelos estudiosos das línguas de sinais se dirigiram, sobretudo, ao convencimento dos linguistas e dos agentes de política linguística de que elas eram, de fato e de direito, línguas. O que ocorria até então era uma compreensão equivocada de que as línguas de sinais eram universais e de que eram facilmente compreendidas por qualquer pessoa (QUADROS, 2019). Até que alcançasse o reconhecimento como língua, a redução da Libras a uma mera forma de comunicação gestual se refletiu nas políticas linguísticas oficiais, a exemplo da Lei de Libras de Pernambuco de 1999. Contudo, há uma amenização da adesão enunciativa do Estado a tais definições apresentadas no Art. 1 pela utilização da partícula apassivadora “-se”: "Compreende-se, como Língua Brasileira de Sinais - LIBRAS [...]" (PERNAMBUCO, 1999). Assim, ao mesmo tempo em que não se atribui a ninguém (nem ao Estado) a responsabilidade enunciativa pela definição, ela é generalizada a partir da universalização da afirmativa.

$\mathrm{Na}$ Figura 2, esquematizamos as construções textuais em que a Libras aparece

\footnotetext{
${ }^{2}$ A grafia correta da sigla da Língua Brasileira de Sinais, a qual adotamos no nosso texto, é Libras, por tratar-se de um siglema, ou seja, "sigla que apresenta caráter de palavra, grafada sem pontos intermediários [...]" (SIGLEMA, 2020). No entanto, decidimos manter o registro da sigla LIBRAS em alguns dos documentos pertencentes ao nosso corpus, com o objetivo de preservar o texto com suas características originais, considerando também que o reconhecimento do registro desse siglema, pelo Manual de comunicação do Senado, só ocorreu em 2012 (LIBRAS, 2012).
} 
como sujeito de orações na referida lei, segundo o ordenamento canônico da Língua Portuguesa (sujeito + verbo + objeto), embora no Art.1 e no Art.3, parágrafo único, essa ordem esteja invertida no texto legislativo.

Figura 2 - Libras na Lei de Pernambuco de 1999

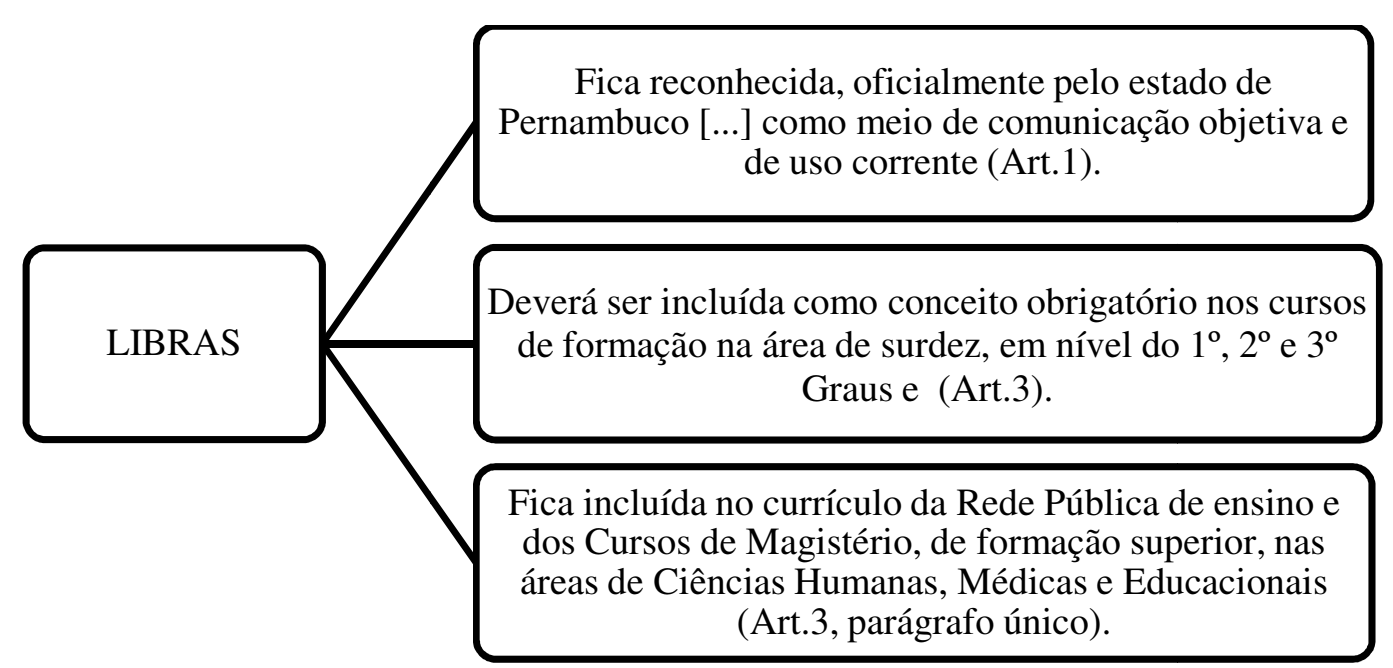

Fonte: Elaboração própria das autoras.

No Art.1 e no Art.3, parágrafo único, há a presença do verbo com função de marcador de pressuposição "ficar", que, segundo Koch (2000, 2011), indica mudança de estado. A utilização da ordem invertida (verbo + sujeito + objeto) topicaliza o verbo, realçando a autoridade da lei em modificar o estado de coisas no mundo (uma língua que não era reconhecida passa a sê-lo, uma língua que não era incluída no currículo passa a sêlo, por meio do texto legislativo). No caput do Art.3, a presença do verbo mais característico da modalidade deôntica ("Deverá”) é reforçada pelo acréscimo do qualificativo "(conceito) obrigatório" para intensificar a obrigatoriedade de inclusão da língua em cursos de formação de surdez em todos os níveis.

A lei de 1999 dispõe sobre as atribuições dos seguintes atores sociais no texto: a Rede Pública de Ensino e a Administração Pública, direta, indireta e fundacional, ambas através da Secretaria de Educação e Esportes, mencionada sempre entre vírgulas por meio de aposto explicativo (à exceção do Art.7, em que tal especificação não aparece).

A Rede Pública de ensino recebe a incumbência, indicada pela modalidade deôntica em "deverá”, de garantir acesso à educação bilíngue em Libras e Língua 
Portuguesa, em todos os níveis educacionais, a todos os alunos portadores de surdez (Art.2). No entanto, no texto da lei não se define o que se entende por educação bilíngue, deixando margem para a interpretação sobre o espaço da Libras e da Língua Portuguesa em cursos de tal natureza. Por sua vez, a Administração Pública, direta, indireta e fundacional recebe a incumbência deque:

[...] manterá, em seus quadros funcionais,profissionais portadores de surdez bem como intérpretes [...] LIBRAS, no processo ensinoaprendizagem, desde a educação infantil até os níveis mais elevados de ensino em suas instituições, garantindo inclusive o material didático porventura necessário a essa aprendizagem. (Art.4).

[...] oferecerá [...] cursos para formação de intérpretes da Língua Brasileira de Sinais - LIBRAS. (Art.5).

[...] oferecerá cursos periódicos de [...] LIBRAS, em diferentes níveis, para portadores de surdez e seus familiares, professores do ensino regular e comunidade em geral. (Art.6).

[...] manterá em suas repartições públicas estaduais, bem como nos estabelecimentos bancários e hospitalares públicos, o atendimento aos portadores de surdez, utilizando profissionais intérpretes da [...]. LIBRAS (Art.7).

(PERNAMBUCO, 1999).

O empenho da Administração Pública de Pernambuco com uma política linguística para a Libras fica textualmente marcado pela utilização dos modalizadores deônticos “manterá" e "oferecerá", a serem lidos como “deverá manter”, “deverá oferecer”, dadas as características normativas do gênero textual "lei". Por esse mesmo motivo, o comprometimento enunciativo se traduz em comprometimento no âmbito das práticas, na medida em que a publicação da referida lei, dessa forma textualizada, fornece um fundamento para a reivindicação de direitos nela previstos pelos cidadãos surdos.

Contudo, mencionamos que tal comprometimento enunciativo e prático não é tirânico, na medida em que constatamos, no Art.4, a presença de elementos linguísticos que buscam realçar o papel provedor do Estado ("garantindo inclusive o material didático"), ao mesmo tempo em que concedem espaço para que o ente estatal delibere a respeito da necessidade das possíveis reivindicações ("porventura necessário a essa aprendizagem"). Segundo Koch $(2000,2011)$, “inclusive” é um operador que indica o 
argumento mais forte em direção a uma determinada conclusão, nesse caso, o de que o Estado se dispõe a fornecer as condições necessárias ao processo de ensino-aprendizagem dos surdos. De acordo com a autora, podemos identificar que o "porventura" trata-se de uma modalização epistêmica, ou seja, um modo de dizer que implica o âmbito das crenças, nesse caso, duvidosas, na mesma tônica do "talvez". A orientação argumentativa, então, aponta que o mais importante é que o Estado vai fornecer o material didático, deixando em segundo plano as variáveis que podem interferir no processo.

Por fim, gostaríamos de chamar a atenção para a recorrência da expressão “portadores de surdez" (presente nos Art. 2, 3, 4, 6 e 7), que gera efeitos de sentido diferentes da expressão "surdo" (presente na ementa da lei e no parágrafo único do Art. 3). Enquanto a primeira indica algo que se "porta" ou que se "tem" (acessório), a segunda remete a algo que se "é" (identidade). A escolha linguística por "portadores de surdez" evoca o conceito de corpo danificado, que "remete a questões de necessidade de normalização, o que significa trabalhar o sujeito surdo do ponto de vista do sujeito normal ouvinte" (PERLIN, 2016, p. 53), em oposição ao reconhecimento do conjunto de construções sociais e culturais que definem o surdo. Nesses termos, a dualidade polifônica,que é um traço dessa lei, é representada aqui pela voz dos ouvintistas ${ }^{3}$ e da comunidade surda. Essa oscilação da referenciação aos sujeitos para quem a Libras "pertenceria" dá testemunho do momento histórico de debates sobre o estatuto do surdo e da Libras.

Destacamos o pioneirismo da lei estadual de reconhecimento da Libras em Pernambuco, primeiro estado nordestino a fazê-lo nesse nível, promulgada três anos antes da Lei Federal $n^{\circ}$ 10.436/2002 que reconheceu a Libras no Brasil ${ }^{4}$. Atribuímos muito desse pioneirismo ao fortalecimento da atuação dos movimentos e das associações surdas do estado, como o Centro de Apoio aos Surdos (CAS), o Centro SUVAG ${ }^{5}$ de Pernambuco, a Associação de Surdos de Pernambuco (ASSPE) e suas extensões municipais, além da

\footnotetext{
${ }^{3}$ Segundo Skliar (2016, p. 15), ouvintismo "trata-se das representações dos ouvintes sobre a surdez e sobre os surdos".

${ }^{4}$ Alguns dos outros estados que se anteciparam à lei federal foram Minas Gerais (1991), Mato Grosso do Sul (1996), Rio de Janeiro (1999) e Paraná (1998). No mesmo ano de Pernambuco, 1999, o Rio Grande do Sul também reconheceu a língua. Em outros estados do Nordeste, o reconhecimento da Libras acontece: no Ceará (2001); no Maranhão (2007); no Rio Grande do Norte (2009); e em Sergipe (2011). Não encontramos dados de leis estaduais promulgadas por Alagoas, Bahia, Paraíba e Piauí.

5 SUVAG é a sigla de Sistema Universal Verbotonal de Audição Guberina, filosofia norteadora da Instituição.
} 
filial regional da Federação Nacional de Educação e Integração dos Surdos (FENEIS).

\section{Lei no 12.252, de 08 de julho de 2002 - Plano Estadual de Educação de 2002}

Três anos depois da lei de Libras de Pernambuco, algumas provisões sobre a inserção da língua na educação estadual aparecem na Lei $n^{0} 12.252$, de 08 de julho de 2002, que aprova o Plano Estadual de Educação de 2002 (doravante PEE), com duração prevista para 10 anos. A título de comparação, nesse mesmo ano, o Brasil (2002) reconhecia oficialmente a Libras.

No PEE de 2002, a Libras aparece nos objetivos e metas estabelecidas para o Ensino Médio:

6 - Reorganizar, racionalmente, em cinco anos, pelo menos $50 \%$ das escolas do ensino médio, e em 10 anos a totalidade das escolas de forma a atender o padrão básico de infra-estrutura definido para o Estado, incluindo: [...] k) implementar, na Escola do Jovem, núcleos de LIBRAS e Tiflologia para atender às necessidades dos alunos surdos e cegos (PERNAMBUCO, 2002, p. 40, grifos nossos).

Nesse excerto, os núcleos de Libras aparecem sob a perspectiva da infraestrutura escolar do Estado. De maneira mais específica, os núcleos deveriam ser implementados na Escola do Jovem e representariam, portanto, parte indispensável do funcionamento e da manutenção da educação básica. Dessa forma, a Libras, tal como representada no texto,passa a ocupar um papel fundamental no domínio escolar (SPOLSKY, 2004, 2009), abrindo caminho para a luta pela garantia do espaço do surdo no Ensino Médio. Esse argumento se reforça quando resgatamos as diretrizes da Escola do Jovem como uma iniciativa do governo federal, junto ao estadual, para garantir maior acesso, incentivar a permanência e o êxito do estudante nesse nível de ensino (PERNAMBUCO, 2002).

Mais à frente, o PEE de 2002 traça um diagnóstico da Educação Especial no Estado, atribuindo-lhe uma atuação positiva: "EDUCAÇÃO ESPECIAL: [...] ações de capacitação em serviço vêm sendo implementadas sistematicamente, destacando-se os cursos de Língua Brasileira de Sinais - LIBRAS, Sistema Braille e equipamento de cálculo, voltados, também, para a comunidade (PERNAMBUCO, 2002, p.57). No excerto, a oferta de cursos de Libras aparece em destaque, possivelmente, como uma decisão no 
âmbito das práticas, resultante do reconhecimento da língua de sinais no estado (PERNAMBUCO, 1999) e no país (BRASIL, 2002).

No PEE de 2002, a Libras também aparece em duas metas específicas relacionadas à Educação Especial:

8 - Ampliar, em 10 anos, o ensino da Língua Brasileira dos Sinais para todos os alunos surdos e professores, mediante programa reconhecido pela Federação Nacional de Surdos. [...]

20 - Implementar, na Escola do Jovem, núcleos de LIBRAS e TIFLOLOGIA para atender às necessidades dos alunos surdos e cegos.

(PERNAMBUCO, 2002, p. 60-61, grifos nossos).

A meta 8 é ambiciosa, tendo em vista a sua aspiração de universalizar o ensino da Libras aos alunos e professores do Estado, o que parece ser uma demanda ainda não resolvida (PERNAMBUCO, 2017). No Plano de 2002, aparece um agente representativo dos surdos em nível nacional (a FENEIS), diante do qual o Estado deveria submeter seu programa formativo na língua, reconhecendo-a como uma autoridade no que diz respeito à Libras. Não poderia ser diferente, visto que o papel da federação é de implementar ações que posicionem o surdo socialmente, mediante a ampla divulgação da língua de sinais, bem como da cultura e história surdas.

Coerente com a proposta de implementar o atendimento especializado nos Núcleos de Libras, a fim de atender as necessidades dos alunos surdos, o PEE de 2002 dispõe de uma meta direcionada à formação continuada dos profissionais do ensino:

14 - Propor às instituições públicas de ensino superior a criação de cursos de graduação e pós-graduação em Educação Especial na capital e interior garantindo, em cinco anos, a realização de pelo menos um curso. (PERNAMBUCO, 2002, p. 61, grifos nossos).

A modalidade deôntica, inferida através dos verbos “(deverá) propor” e “(devendo) garantir", sugere uma preocupação do Estado com a formação dos profissionais do ensino e um papel normalizador, mas exime-o da responsabilidade direta pela sua realização. Nesse sentido, um novo agente é encarregado do alcance da meta: as instituições de ensino superior. Como exemplo concreto da implementação de medidas em direção ao 
cumprimento da meta, no que tange especificamente à educação em Libras, entre 2008 e 2009, a Faculdade Santa Helena, em parceria com a Secretaria de Educação do Estado e autorizada pelo Conselho de Ética da Universidade Federal de Pernambuco (UFPE), ofertou o curso de Especialização "Educação Especial: Estudos Surdos”. Mais de 40 monografias foram defendidas, elaboradas a partir de um relatório denominado de "Figurações culturais: surdos na contemporaneidade", resultado da geração de dados sobre os surdos no estado.

O PEE de 2002 aponta para um amadurecimento da relação do Estado com a Libras. Isso se deve, possivelmente, ao gerenciamento linguístico resultante de legislações anteriores e das práticas da própria comunidade surda. Nesse âmbito, no mesmo ano de 2002, iniciou-se o movimento da Passeata dos Surdos, reunindo centenas de surdos nas ruas do Recife, para apresentar pautas reivindicatórias ao governo (FERRAZ, 2009).

Outro ponto de destaque no mecanismo de política linguística representado pelo PEE de 2002 é a descentralização das responsabilidades. Logo, percebemos um direcionamento das ações idealizadas pelo Estado a outros agentes, como as instituições de ensino superior e a FENEIS, promovendo, assim, parcerias entre as instituições públicas e a sociedade civil.

\section{Lei $\mathbf{n}^{0}$ 12.757, de 24 de janeiro de 2005}

Embora o Plano da Educação de Pernambuco (2002) coloque alguns objetivos para a educação em Libras no Estado, ele não contempla diretamente a formação de professores e de intérpretes da língua, como previsto na Lei Estadual de Libras de 1999. Tais provisões seriam tomadas pela Lei ${ }^{\circ}$ 12.757, de 24 de janeiro de 2005, que criou, no Quadro de Empregos do Poder Executivo, o Grupo Magistério Público para Educação Especial.

O Art. 2 da referida lei criou as funções de Professor Intérprete de Língua Brasileira de Sinais (Nível Superior), de Professor Intérprete de Língua Brasileira de Sinais (Nível Médio) e de Professor Instrutor de Língua Brasileira de Sinais (Nível Médio). Além disso, especificou requisitos para a contratação desses profissionais, salário-

\footnotetext{
${ }^{6}$ Para ter acesso ao relatório: <http://www.suvag.org.br/topicos/relato.html>. Acesso em: 22 abr. 2020. 
base e carga horária de trabalho, bem como a quantidade de vagas designadas para cada função. O Anexo I do texto legal descreve as atribuições de cada função, as quais são resumidas a seguir.

Em comum, todas as três funções receberam a atribuição de participar na escolha do livro didático, participar de estudos e pesquisas na sua área de atuação, participar da elaboração e gestão da proposta pedagógica da escola em uma ação coletiva com os demais segmentos, participar da avaliação institucional do sistema educacional do estado e executar atividades correlatas. Além dessas, o Intérprete de Nível Superior e o de Nível Médio compartilhariam a atribuição de interpretar em Língua Brasileira de Sinais/Língua Portuguesa as atividades didático-pedagógicas e culturais desenvolvidas nas instituições de ensino que ofertam educação básica, superior e/ou educação profissional.

Específicas do Professor Intérprete de Nível Superior seriam as atribuições de participar da formação de intérpretes em Libras, produzir e publicar textos pedagógicos, participar da promoção e coordenação de reuniões, encontros, seminários, cursos, eventos da área educacional e correlatas, e participar da elaboração e avaliação de propostas curriculares. Já específicas do Professor Instrutor de Libras de Nível Médio seriam as atribuições de ministrar aulas práticas de Língua Brasileira de Sinais,apoiar o trabalho do professor na transmissão da Língua Brasileira de Sinais e orientar a aplicação de metodologia no ensino de Libras.

Menos de um ano depois, essa lei foi revogada pelo Art. $9^{\circ}$ da Lei ${ }^{\circ} 12.980$, de 29 de dezembro de 2005, e os cargos por ela criados foram transformados em cargos públicos do grupo de magistério, orientados pelo regime jurídico do estado,com o reconhecimento do vencimento e de todos os benefícios sobre o exercício da profissão (PERNAMBUCO, 2005b). Contudo, a sua promulgação contribuiu com o movimento de curricularização da Libras no estado, na medida em que criou funções do magistério específicas para desempenhar as atividades direcionadas ao ensino de surdos a partir da Libras.

\section{Lei no 15.533, de 23 de junho de 2015 - Plano Estadual de Educação de 2015}

No ano de 2015, Pernambuco promulga um novo PEE, válido para os anos de 2015 a 2025. Tendo como algumas de suas diretrizes a universalização do atendimento escolar; a superação das desigualdades educacionais, com ênfase na promoção da 
cidadania e na erradicação de todas as formas de discriminação; e a promoção dos princípios do respeito aos direitos humanos, à diversidade e à sustentabilidade socioambiental, o PEE de 2015 amplia significativamente as disposições sobre a educação especial e, especificamente, dos surdos (PERNAMBUCO, 2015a).

O Anexo único da lei estabelece metas e estratégias a serem alcançadas e perseguidas no decênio previsto (2015-2025), e a educação especial aparece com destaque nas Metas 4, 15 e 16. A Meta 4 refere-se à universalização do atendimento escolar aos alunos com deficiência entre quatro a dezessete anos. Dentre as estratégias a serem perseguidas para a concretização da Meta 4, todas mais ou menos relevantes para a educação dos surdos, selecionamos as seguintes que tratam nominalmente da Libras:

\begin{abstract}
4.1. Fortalecer a educação inclusiva, em regime de colaboração com os entes federados, garantindo acessibilidade no espaço escolar, através de mobiliários, equipamentos e transporte escolar adequados à pessoa com deficiência; uso de libras, braile e comunicação suplementar alternativa; material didático apropriado; e oferta de educação bilíngue em Língua Portuguesa e Língua Brasileira de Sinais. [...]
\end{abstract}

4.11. Garantir e ampliar as equipes de profissionais da educação para atender à demanda do processo de escolarização dos estudantes com deficiência, transtornos globais do desenvolvimento, transtornos do espectro autista e altas habilidades ou superdotação, garantindo a oferta de professores do atendimento educacional especializado, de profissionais de apoio ou auxiliares, tradutores ou intérpretes de libras, guias intérpretes para surdo cegos e professores de libras e braile. [...]

4.21. Disponibilizar nos espaços escolares tradutores, intérpretes e outros profissionais de apoio, que auxiliem na comunicação, alimentação, higiene e locomoção dos estudantes com deficiência, transtornos globais de desenvolvimento, transtornos do espectro autista $\mathrm{e}$ altas habilidades ou superdotação.

(PERNAMBUCO, 2015, p. 65, grifos nossos).

Na estratégia 4.1, para o fortalecimento da educação inclusiva e da acessibilidade no espaço escolar, coloca-se a mediação do uso da Libras e da oferta de educação bilíngue em Língua Portuguesa e em Língua Brasileira de Sinais. Chama a atenção a oscilação na nomenclatura da língua, que ora parece ser compreendida como meio de comunicação (Libras), que permite que o sujeito surdo acesse o espaço escolar sem tolher suas 
características socioculturais;ora como uma língua institucionalizada (Língua Brasileira de Sinais), que deve ser ensinada a partir de seus elementos morfossintáticos, semânticos e pragmáticos, assim como a Língua Portuguesa. Parece haver aqui, portanto, um esforço significativo de tornar a Libras uma língua funcional no domínio escolar (SPOLSKY, 2004, 2009) e não apenas uma parte da burocracia curricular.

Esse dispositivo legal, ainda, compromete o Estado a garantir e ampliar o número de profissionais de educação voltados ao atendimento dos estudantes com deficiência, dentre eles tradutores e intérpretes de Libras, guias intérpretes para surdo-cegos ${ }^{7}$ e professores de Libras. Destacamos aqui a entrada dos surdo-cegos na abrangência do PEE de2015, provavelmente em virtude da regulamentação da profissão de tradutor e intérprete de Libras, que ocorreu mediante a promulgação da Lei Federal $\mathrm{n}^{\circ} 12.319$, de setembro de 2010, que prevê como atribuição do profissional tradutor e intérprete: "I - efetuar comunicação entre [...] surdos e surdos-cegos, surdos-cegos e ouvintes, por meio da Libras para a língua oral e vice-versa" (BRASIL, 2010, grifos nossos). Antes dessa lei, os surdo-cegos eram incluídos nos termos das pessoas com deficiências sensoriais. A esses profissionais o Estado se compromete a disponibilizar espaços escolares para que auxiliem, também, na comunicação, pelo que subentendemos a Libras, no caso dos estudantes surdos.

Já as Metas 15 e 16 tratam da formação e valorização de profissionais da educação. As estratégias 15.12 e 16.6 versam mais diretamente sobre a relação entre essa formação e a Libras:

15.12. Garantir e ampliar as equipes de profissionais da educação para atender à demanda do processo de escolarização dos estudantes com deficiência, transtornos globais do desenvolvimento, transtornos do espectro autista e altas habilidades ou superdotação, garantindo a oferta de professores do atendimento educacional especializado, de profissionais de apoio ou auxiliares, tradutores ou intérpretes de libras, guias intérpretes para surdocegos e professores de libras e braile (PERNAMBUCO, 2015, p.78, grifos nossos).

16.6. Implantar cursos de pós-graduação na área de Atendimento Educacional Especializado(AEE) e Letras Libras nas universidades públicas do Estado (PERNAMBUCO, 2015, p.79, grifos nossos).

\footnotetext{
${ }^{7}$ Estamos cientes que há uma diferença terminológica entre surdo-cego e surdocego, conforme aponta Lagati (1995, p. 306 apud BOSCO; MESQUITA; MAIA, 2010) mas, neste estudo, optamos por manter a mesma grafia da lei.
} 
De início, o compromisso de não só garantir, mas também ampliar a oferta de profissionais que possam atender os estudantes com deficiência é reafirmado, e os tradutores ou intérpretes de Libras, os guias intérpretes para surdo-cegos e os professores de Libras são singularizados como profissionais necessários a essa ampliação. Para tanto, a legislação educacional do Estado dá um passo à frente na disponibilização de oportunidades de formação em Libras em nível de pós-graduação na própria instituição superior pública do Estado: a Universidade Estadual de Pernambuco (UPE). A Resolução CEPE nº 064/2014 da Reitoria da UPE, por exemplo, aprovou o curso de Especialização em Educação Especial na Perspectiva Inclusiva e Especialização em Libras no campus Mata Norte (UPE, 2014). Posteriormente, em virtude da Resolução CEPE nº 43/2018, esse curso se desmembrou para o curso de Especialização em Libras (UPE, 2018). Outra resolução criou o curso de Especialização em Libras no campus Garanhuns, através da Resolução CEPE nº 011/2016 (UPE, 2016).

Em termos gerais, o PEE de 2015 é um mecanismo de política linguística que se preocupa com a manutenção e a ampliação dos dispositivos anteriores que já regulam o Libras no domínio escolar (SPOLSKY, 2004, 2009), buscando garantir a qualidade da educação inclusiva, a formação continuada e a ampliação dos recursos para valorização e naturalização da Libras nas escolas.

\section{Edital $n^{\circ}$ 01, de 11 de dezembro de 2015 - Portaria conjunta SAD/SEE $n^{\circ} 111$ de 11 de dezembro de 2015}

Por fim, as previsões para a ampliação da oferta de professores para a educação especial, contidas na Lei n. 12.757 de 2005 e no Plano Estadual de Educação de 2015, materializam-se na publicação do edital para Concurso Público de Provas e Títulos para o Magistério Público para Educação Especial através da Portaria conjunta SAD/SEE no 111 de 11 de dezembro de 2015. O concurso contemplou 53 vagas para Professor Intérprete de Língua Brasileira de Sinais (Nível Superior), 124 para Professor Intérprete de Língua Brasileira de Sinais (Nível Médio) e 88 para Professor Instrutor de Língua Brasileira de Sinais (Nível Médio). As atribuições dos cargos são as mesmas especificadas na Lei de 2005.

O certame visou selecionar os candidatos aos cargos com base em conhecimentos 
gerais (Língua Portuguesa e Conhecimentos Pedagógicos) e específicos. Os conhecimentos específicos para o cargo de Professor Intérprete de Libras (Nível Superior) permitem traçar um perfil do profissional desejado pela Administração estadual como sendo aquele que: i) conhece a legislação nacional pertinente à educação especial; ii) conhece declarações internacionais sobre o assunto; iii) tem uma visão normativa, histórica, conceptual, transcritora do sistema linguístico da Libras, tudo aplicado à conversação. Já o perfil do candidato a Professor Instrutor de Libras (Nível Médio) previsto pelo edital é aquele que: i) conhece a legislação nacional pertinente à educação especial; ii) conhece a legislação específica na área de surdez e a história geral da educação dos surdos; iii) tem uma visão clínica e antropológica da surdez, aliada à sua aplicação a modelos educacionais; iv) compreende as identidades surdas, seus locais e sua cultura; v) domina o sistema linguístico da Libras; vi) conhece as normativas do FENEIS e do estado de Pernambuco atinentes ao papel de instrutor de Libras.

Outro fator relativo à política linguística de seleção de professores de Libras no Estado se refere à certificação na língua. Os requisitos para investidura nos cargos, presentes na parte intitulada "Do processo de seleção" do edital, são:

3.3.1 Os candidatos com nível superior completo concorrente as vagas de Professor Intérprete de Língua Brasileira de Sinais [...] deverão no prazo de 3 (três) anos apresentar comprovação de formação em Licenciatura Plena.

3.3.2 Os candidatos com nível médio concorrente as vagas de Professor Intérprete de Língua Brasileira de Sinais, Professor Instrutor de Língua Brasileira de Sinais [...], deverão no prazo de 3 (três) anos apresentar comprovação de formação em Licenciatura Plena em Pedagogia ou Normal Médio.

(PERNAMBUCO, 2015b, grifos nossos).

Podemos inferir que o edital alarga o prazo de comprovação por entender que não havia profissionais suficientes com grau de qualificação certificada por instituições de ensino superior compatível com as vagas disponibilizadas. Além de a formação dos intérpretes, historicamente, ter sua origem na sociedade civil, por meio das igrejas (SILVA, 2010), o curso superior em Letras Libras da UFPE abriu a sua primeira turma apenas em 2014. Outrossim, a exigência pela qualificação dos profissionais em 
licenciaturas e Cursos Normais legitima a inclusão desses profissionais no quadro do magistério, como disposto em Pernambuco (2005b).

\section{Instrução Normativa SEE No 007/2017}

A Secretaria Estadual de Educação de Pernambuco publicou, no ano de 2017, a Instrução Normativa $\mathrm{n}^{\circ}$ 007, com o objetivo de estabelecer procedimentos e normas para a realização do Cadastro Escolar e da Matrícula do(a) estudante, na Educação Básica da Rede Estadual de Ensino do Estado de Pernambuco (PERNAMBUCO, 2017). A menção explícita ao surdo e à Libras aparece nos Art. 35 e 69, que assim dispõem:

Art. 35. Aos(Às) estudantes surdos(as), cegos(as), e com baixa visão ou surdo-cegos(as) serão assegurados(as), respectivamente, de acordo com a deficiência, professor(a) intérprete, professor(a) brailista e guia intérprete (PERNAMBUCO, 2017, p. 11).

Art. 69. No Ensino Fundamental e no Ensino Médio, a oferta do ensino da Língua Brasileira de Sinais - LIBRAS será obrigatória para a Escola e de matrícula facultativa para o(a) estudante, conforme disposto na Lei Federal $\mathrm{n}^{\mathrm{o}} 10.436 / 2002$ e no Decreto Federal $\mathrm{n}^{\circ}$ 5.626/2005, cabendo ao(à) estudante ou seu responsável fazer a opção de cursar o citado componente curricular no ato da matrícula (PERNAMBUCO, 2017, p. 12).

O Art. 35 textualiza um comprometimento do governo, representado pela escolha da modalidade deôntica "serão assegurados", com a garantia da qualidade do ensino e de permanência dos alunos surdos na escola, com o apoio dos profissionais capacitados. Além disso, valoriza o processo formativo do sujeito a partir de suas características sociais e culturais, dispondo o lugar da Libras como língua materna.

Acentuando o estatuto da Libras erigido no domínio escolar (SPOLSKY, 2004, 2009) pelo novelo de leis estaduais anteriores, de forma imperativa (“será obrigatória”), o Art.69 atribuí à língua de sinais um papel inédito no âmbito estadual, na medida em que se expande a obrigatoriedade de sua oferta para as escolas da educação básica, fazendo avançar a curricularização da Libras, à frente das legislações federais.

Quanto à sua implementação, a normativa esbarra na "cacofonia das crenças e ideologias" (JOHNSON, 2013, p. 113) dos estudantes e responsáveis. Ao presumir, 
através do índice de avaliação "facultativa", que cabe a eles a opção de cursar ou não a disciplina, deixa-se a decisão a cargo dos valores individuais atribuídos à língua, bem como das experiências dos usuários. Isso pode ser um impedimento para o fortalecimento do estatuto da Libras no domínio escolar, uma vez que seu uso ainda parece vinculado apenas à inclusão e à solidariedade, com a persistência de crenças que não a reconhecem como língua de fato e, portanto, passível de ser dispensada na formação escolar do aluno surdo.

\section{Currículo de Pernambuco e Regimento Interno Unificado}

Em 2019, dois documentos foram adicionados ao percurso normativo para a Libras na educação de Pernambuco: o Currículo para Educação Infantil e para o Ensino Fundamental, e o Regimento Interno Unificado (PERNAMBUCO, 2019a, 2019b). No Currículo, a Libras é citada unicamente nas competências gerais para os dois segmentos (Infantil e Fundamental), e nas competências específicas para linguagem no Ensino Fundamental:

\footnotetext{
Utilizar diferentes linguagens - verbal (oral ou visual-motora, como Libras, e escrita), corporal, visual, sonora e digital - para se expressar e partilhar informações, experiências, ideias e sentimentos em diferentes contextos e produzir sentidos que levem ao diálogo, à resolução de conflitos e à cooperação. (PERNAMBUCO, 2019a, p. 17, grifos nossos).
}

Tal competência reproduz textualmente uma das competências previstas na Base Nacional Comum Curricular (BNCC) (BRASIL, 2018). O texto disposto no documento estadual replica o documento nacional, sem fazer referência à Instrução Normativa SEE $n^{\circ}$ 007, que já havia disposto a inserção curricular da Libras como disciplina escolar. Ao absorver ipsis litteris a BNCC, o Currículo de Pernambuco, consequentemente, acaba reproduzindo a voz do Decreto nacional no 5.626/2005, o qual reconhece a língua de sinais, mas mantém a hegemonia da gramática normativa da Língua Portuguesa (BRASIL, 2005). Deixa, assim, de mencionar o avanço representado pela Instrução Normativa estadual, uma vez que, nacionalmente, a inserção da Libras nos currículos da educação básica ainda tramita no Senado Federal sob a PL nº 5.961/2019 (BRASIL, 2019b). 
O Regimento Interno Unificado regulamenta a estruturação pedagógicoadministrativa e de convivência social das Unidades Escolares da Rede Estadual de Ensino de Pernambuco. Na exigência de ofertar condições justas para a avaliação da aprendizagem do surdo, a lei dispõe sobre a obrigatoriedade do profissional de apoio para o "estudante com deficiência auditiva ou surdez" (PERNAMBUCO, 2019b, p. 08), ao empregar o deôntico "deverão ser apoiados". Ainda que os termos "deficiente auditivo" e "portador de surdez" nos levem, novamente, à discussão sobre corpos danificados, há um esforço da normativa em reconhecer a condição identitária do surdo, no inciso II, ao prever que uma avaliação da aprendizagem, que privilegie a vivência social, pode abrir portas para que o surdo seja aceito na sua condição e interaja na sua língua natural (PERNAMBUCO, 2019b).

\section{CONSIDERAÇÕES FINAIS}

Neste artigo, discutimos as políticas linguísticas educacionais oficiais do estado de Pernambuco voltadas para a Libras, no período de 1999 a 2019, com base em uma amostra de documentos oficiais. Constatamos que a política oficial tem se realizado por meio de dispositivos materializados em leis, planos de educação, editais de concurso, instrução normativa, currículos e regimento interno, que normatizam desde o estatuto da língua até as metas educacionais relacionadas ao seu ensino, o perfil dos profissionais atuantes e a matrícula escolar dos alunos surdos. Evidenciamos como os documentos oficiais analisados representam o gerenciamento linguístico exercido por Pernambuco, que aciona diversos mecanismos para fortalecer a Libras no sistema educacional do estado, sendo tais documentos formulados em um processo dinâmico e interativo que resulta em textos que refletem diversas vozes sociais.

Contudo, o Relatório Parcial da Frente Parlamentar em Defesa da Pessoa com Deficiência de Pernambuco indica que há ainda muita distância entre a caneta do legislador e do administrador estadual e o "chão" da escola. Dentre os problemas no domínio escolar apontados, encontram-se a carência de intérpretes de Libras e de material didático (PERNAMBUCO, 2018). O relatório registra como demandas: 
- $\quad$ Contratação de professores surdos para pessoas com deficiência auditiva, pois muitas vezes $o$ intérprete de Libras não tem 0 conhecimento necessário da matéria, dificultando o aprendizado.

- Implantar cursos de pós-graduação em Letras Libras nas universidades públicas do estado, conforme estratégia do Plano Estadual de Educação. [...]

- A contratação de professores surdos, pois muitas vezes o intérprete de Libras não tem o conhecimento necessário para repassar o conteúdo.

(PERNAMBUCO, 2018, p. 47).

A reiteração da demanda por intérpretes de Libras mais qualificados nas matérias escolares evidencia um aspecto da formação dos profissionais não incluído nos documentos oficiais. Sugere-se, assim, a necessidade de repensar os critérios de formação exigidos para o profissional ou de formá-los em serviço, de maneira a atuarem como facilitadores do processo de ensino-aprendizagem do aluno surdo. Além disso, a demanda por mais cursos de pós-graduação em Letras Libras continua premente, o que indica a necessidade de profissionais qualificados na língua para atender aos estudantes surdos.

A discussão sobre a política linguística educacional pernambucana foi iniciada por Andrade (2016), ao investigar o processo de interpretação e de apropriação dos Parâmetros de Língua Portuguesa por professores do estado. Este artigo contribui com a explicitação de mais um aspecto da política linguística educacional de Pernambuco, desta feita enfocando a Libras, demonstrando que muito já vem sendo feito, mas ainda há muito a se fazer, de maneira a incluir o surdo pernambucano com qualidade na educação escolar, propiciando condições para que atinja todas as suas potencialidades cidadãs, acadêmicas, profissionais e humanas.

\section{REFERÊNCIAS}

ANDRADE, R. C. O. Políticas linguísticas educacionais em Pernambuco: um estudo do eixo de análise linguística. 2016. 198f. Dissertação (Mestrado em Linguística) Universidade Federal da Paraíba, João Pessoa, 2016. Disponível em: $<$ https://repositorio.ufpb.br/jspui/bitstream/123456789/11626/1/Arquivototal.pdf $>$. Acesso em: 20 abr. 2020

BRASIL. Base Nacional Comum Curricular. 2018. Disponível em: $<$ http://basenacionalcomum.mec.gov.br/images/BNCC_EI_EF_110518_versaofinal_site.p df>. Acesso em: 30 abr. 2020. 
Lei $n^{\circ}$ 10.436, de 24 de abril de 2002. Dispõe sobre a Língua Brasileira de Sinais Libras e dá outras providências. Diário Oficial da União, Brasília, DF, 25 de abr. 2002. Disponível em: <http://www.planalto.gov.br/ccivil_03/leis/2002/110436.htm>. Acesso em: 20 abr. 2020.

Decreto $n^{\circ} 5.626$, de 22 de dezembro de 2005. Regulamenta a Lei $\mathrm{n}^{\circ} 10.436$, de 24 de abril de 2002, que dispõe sobre a Língua Brasileira de Sinais - Libras, e o art. 18 da Lei n 10.098, de 19 de dezembro de 2000. Diário Oficial da União, Brasília, DF, 23 dez. 2005. Disponível em: $\quad<$ http://www.planalto.gov.br/ccivil_03/_Ato20042006/2005/Decreto/D5626.htm>. Acesso em: 20 abr. 2020.

Lei $n^{\circ} 12.319$, de $1^{\circ}$ de setembro de 2010. Regulamenta a profissão de Tradutor e Intérprete da Língua Brasileira de Sinais - LIBRAS. Diário Oficial da União, Brasília, DF, 02 set. 2010. Disponível em: <http://www.planalto.gov.br/ccivil_03/_Ato20072010/2010/Lei/L12319.htm >. Acesso em: 20 abr. 2020.

Decreto $n^{\circ}$ 9.465, de 2 de janeiro de 2019. Aprova a Estrutura Regimental e o Quadro Demonstrativo dos Cargos em Comissão e das Funções de Confiança do Ministério da Educação, remaneja cargos em comissão e funções de confiança e transforma cargos em comissão do Grupo-Direção e Assessoramento Superiores - DAS e Funções Comissionadas do Poder Executivo - FCPE. Diário Oficial da União,Brasília, DF, 02 jan. 2019a. Disponível em:

<http://www.in.gov.br/materia/-/asset_publisher/Kujrw0TZC2Mb/content/id/57633286>.

Acesso em: 20 abr. 2020.

PL 5961, de 2019. (em tramitação)Altera a Lei no 9.394, de 20 de dezembro de 1996, que estabelece as diretrizes e bases da educação nacional, para incluir, nos currículos do ensino fundamental e do ensino médio, para todos os alunos, conteúdos relativos à Língua Brasileira de Sinais(Libras).Plenário do Senado Federal, Brasília, DF, 2019b. Disponível em: <https://www25.senado.leg.br/web/atividade/materias/-/materia/139785>. Acesso em: 24 abr. 2020.

FERRAZ, R. de A. O mundo surdo: passeata dos surdos - luta e comemoração. 2009. 81f. Monografia - Faculdade Santa Helena, Recife, 2009.

GIL, A. C. Métodos e técnicas de pesquisa social, 7.ed. São Paulo: Atlas, 2019.

JOHNSON, D. C. Language policy. New York: Palgrave Macmillan, 2013.

KOCH, I. G. V. A inter-ação pela linguagem. 5.ed. São Paulo: Contexto, 2000. . Argumentação e linguagem. 13.ed. São Paulo: Cortez, 2011.

LIBRAS. In: Manual de comunicação. Brasília: Senado Federal, 2012. Disponível em: $<$ https://www12.senado.leg.br/manualdecomunicacao/redacao-e-estilo/estilo/libras $>$.

Acesso em: 23 abr. 2020. 
BOSCO, I. C. M. G.; MESQUITA, S. R. S. H.; MAIA, S. R. A Educação Especial na Perspectiva da Inclusão Escolar : surdocegueira e deficiência múltipla. Brasília: Ministério da Educação, Secretaria de Educação Especial; [Fortaleza]: Universidade Federal do Ceará, 2010. Disponível em: <http://portal.mec.gov.br/docman/novembro-2010-pdf/7107fasciculo-5-pdf/file>. Acesso em: 27 jul. 2020.

PERLIN, G. T. T. Identidades surdas. In: SKLIAR, C. (Org.). Surdez: um olhar sobre as diferenças. 8 ed., Porto Alegre: Mediação, p. 51-73, 2016.

PERNAMBUCO. Lei $n^{\circ} 11.686$ de 18 de outubro de 1999. Reconhece oficialmente no Estado de Pernambuco, como meio de comunicação objetiva e de uso corrente, a Língua Brasileira de Sinais - LIBRAS, e dispõe sobre a implantação desta como língua oficial na Rede Pública de ensino para surdos. Diário Oficial do Estado, Recife, PE, 19 out. 1999. Disponível em: <http://legis.alepe.pe.gov.br/Paginas/texto.aspx?id=2427>. Acesso em: 20 abr. 2020.

Lei $n^{\circ} 12.252$, de 08 de julho de 2002. Aprova o Plano Estadual de Educação e dá outras providências. Diário Oficial do Estado, Recife, PE, 09 set. 2002. Disponível em: $<$ http://legis.alepe.pe.gov.br/texto.aspx?id=3978\&tipo=TEXTOORIGINAL $>$. Acesso em: 20 abr. 2020.

Lei $n^{\circ}$ 12.757, de 24 de janeiro de 2005. Cria, no Quadro de Empregos do Poder Executivo o Grupo Magistério Público para Educação Especial, e dá outras providências. Diário Oficial do Estado, Recife, PE, 25jan. 2005a. Disponível em: $<$ http://legis.alepe.pe.gov.br/texto.aspx?id=3751\&tipo=TEXTOORIGINAL>. Acesso em: 20 abr. 2020.

.Lei $n^{\circ}$ 12.980, de 29 de dezembro de 2005. Institui o Quadro de Pessoal que indica, transforma e extingue empregos nos quadros de pessoal da Universidade de Pernambuco UPE e do Poder Executivo, e dá outras providências.Diário Oficial do Estado, Recife, PE, 30 dez. 2005b. Disponível em $<$ https://legis.alepe.pe.gov.br/texto.aspx?id=4410\&tipo=TEXTOORIGINAL $>$. Acesso em: 23 abr. 2020.

.Lei $n^{o}$ 15.533, de 23 de junho de 2015. Aprova o Plano Estadual de Educação PEE.Diário Oficial do Estado, Recife, PE, 24 jun. 2015a. Disponível em: $<$ https://legis.alepe.pe.gov.br/texto.aspx?tiponorma $=1 \&$ numero $=15533 \&$ complemento $=0 \&$

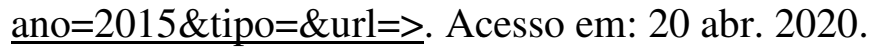

Edital $n^{\circ}$ 02, de 11 de dezembro de 2015 (Portaria conjunta SAD/SEE no 112 de 11 de dezembro de 2015). Abre Concurso Público de Provas e Títulos para o [...]Quadro Permanente de Pessoal do Sistema Público Estadual de Educação, cargo Professor, para diversas disciplinas do currículo regular [...].Secretaria de Administração do Estado e Secretaria de Educação do Estado, Pernambuco, 11 dez. 2015b. Disponível em: $<$ http://www.educacao.pe.gov.br/portal/upload/galeria/9756/Edital\%20Final_magist\%C3\% A9rio\%20regular_11_12_2015.pdf>. Acesso em: 20 abr. 2020. 
Instrução normativa SEE $N^{o}$ 007/2017. Estabelece normas e diretrizes para a organização do ano letivo das Escolas da Rede Estadual de Ensino do Estado de Pernambuco. Diário Oficial do Estado, Recife, PE, 17 nov. 2017. Disponível em: $<$ http://200.238.105.211/cadernos/2017/20171117/1-

PoderExecutivo/PoderExecutivo(20171117).pdf >. Acesso em: 20 abr. 2020.

. Currículo de Pernambuco: Ensino Fundamental - Área de Linguagens. Secretaria de Estado de Educação de Pernambuco, 2019a. Disponível em <encurtador.com.br/dnKMP> . Acesso em: 23 de abr. 2020.

Decreto $n^{o} 48.477$, de 26 de dezembro de 2019. Regimento Estadual Unificado da Rede Estadual de Educação de Pernambuco. Regulamenta a estruturação pedagógicoadministrativa e de convivência social das Unidades Escolares da Rede Estadual de Ensino de Pernambuco. Diário Oficial do Estado, Recife, PE, 27 dez. 2019b. Disponível em: $<$ http://www.sds.pe.gov.br/images/media/1577454923_247\%20BGSDS\%20DE\%2027DE Z2019.pdf> . Acesso em: 23 de abr. 2020.

Assembleia Legislativa do Estado de Pernambuco. Relatório Parcial da Frente Parlamentar em Defesa da Pessoa com Deficiência. Recife: 2018. Disponível em: <http://www.alepe.pe.gov.br/wp-content/uploads/2018/12/RELATORIO-FP-PESSOACOM-DEFICIENCIA.pdf >. Acesso em: 30 abr. 2020.

QUADROS, R. M. de. Libras. 1.ed. São Paulo: Parábola, 2019.

SACKS, O. Vendo vozes. São Paulo: Companhia das Letras, 2010.

SHOHAMY, E. Language policy: hidden agendas and new approaches. Routledge: London, 2006.

SPOLSKY, B. Language policy: key topics in Sociolinguistics. Cambridge: Cambridge, 2004. . Language management. Cambridge: Cambridge University Press, 2009.

SIGLEMA. In: Michaelis dicionário da Língua Portuguesa. São Paulo: Melhoramentos, 2020. Disponível em: <http://michaelis.uol.com.br/busca?id=0LMd8>. Acesso em: $21 \mathrm{abr}$. 2020 .

SKLIAR, C. Surdez: um olhar sobre as diferenças. 8 ed., Porto Alegre: Mediação, 2016.

SILVA, C. A. de A. Entre a deficiência e a cultura: análise etnográfica de atividades missionárias com surdos. 2010. 227f. Tese (Doutorado em Antropologia Social) Universidade de São Paulo, São Paulo, 2010.

UNIVERSIDADE DE PERNAMBUCO. Resolução CEPE 064/2014. Aprova o curso de Especialização em Educação Especial na Perspectiva Inclusiva e Especialização em Libras ambos da UPE Campus Mata Norte e o Curso de Especialização em Medicina do Trabalho 
da FCM. Conselho de Ensino, Pesquisa e Extensão - CEPE, Pernambuco, 28 ago. 2014. Disponível em:

$<$ https://drive.google.com/file/d/1deCFnWQqpIdyht50UtRsAt6GgRxvtoFD/view>. Acesso em: 25 jul. 2020.

. Resolução CEPE 011/2016. Aprova a criação do Curso de Especialização em Libras - Campus Garanhuns. Conselho de Ensino, Pesquisa e Extensão - CEPE, Pernambuco, 25 fev. 2016. Disponível em: $<$ https://drive.google.com/file/d/1Z0V5NhpEb-zlV7aHIveWLOvsRwR1q_3/view>. Acesso em: 25 jul. 2020.

Resolução CEPE 043/2018. Aprova a criação do Curso de Especialização em Libras - Campus Mata Norte da UPE. Conselho de Ensino, Pesquisa e Extensão - CEPE, Pernambuco, 29mai. 2018. Disponível em: <https://drive.google.com/file/d/1CIFvYNVcB81Zjo5LxXCRBpL6f6yWEBa/view>. Acesso em: 25 jul. 2020.

Recebido em: 30 abr. 2020. Aceito em: 05 out. 2020. 